\title{
HUBUNGAN DUKUNGAN KELUARGA DENGAN MOTIVASI PASIEN PASCA STROKE DALAM MELAKUKAN LATIHAN REHABILITASI MEDIK DI POLIKLINIK RSUD PROVINSI NTB TAHUN 2019
}

\author{
Syamsiah $^{1}$, Zulkahfi $^{2}$, Ernawati $^{3}$, Baik Heni Rispawati ${ }^{4}$ \\ ${ }^{1)}$ Mahasiswa Sekolah Tinggi Ilmu Kesehatan (STIKES) Yarsi Mataram \\ ${ }^{2,3,4)}$ Dosen Sekolah Tinggi Ilmu Kesehatan (STIKES) Yarsi Mataram \\ Email: ernawati091984@gmail.com
}

\begin{abstract}
ABSTRAK
Rehabilisasi Stroke merupakan bagian yang sangat penting dari upaya pemulihan pada pasien pasca Stroke.Rehabilisasi Stroke dapat membantu pasien Stroke dalam banyak hal yaitu membangun kekuatan, koordinasi, daya tahan atau ketahanan dan rasa percaya diri.Tujuan penelitian ini untuk mengetahui hubungan dukungan keluarga dengan motivasi pasien pasca stroke dalam melakuakan rehabilitasi medik. Desain Penelitian adalah design korelatif dengan jumlah sampel 50 orang. Penelitian ini dilakukan di Poliklinik Rehabilitasi Medik RSUD Provinsi NTB pada bulan Juli 2019. Alat pengumpul data pada penelitian ini adalah kuesioner. Berdasarkan hasil penelitian didapatkan responden memiliki dukungan keluarga yang baik sebanyak 33 (66\%) dan memiliki motivasi yang baik sebanyak $30(60 \%)$ dan berdasarkan uji analisis Spearman Rank didapatkan P Value 0.000 yang artinya $\alpha<0.1$ sehingga dapat disimpulkan bahwa ada Hubungan Dukungan Keluarga dengan Motivasi Pasien Pasca Stroke dalam Melakukan Latihan Rehabilitasi Medik di Poliklinik RSUD Provinsi NTB Tahun 2019. Saran diharapkan hasil penelitian ini dapat digunakan untuk memperkaya perkembangan ilmu khususnya dalam bidang keperawatan
\end{abstract}

Kata Kunci :Dukungan Keluarga, Motivasi, Rehabilitasi Medik

\section{THE CORRELATION OF FAMILY SUPPORT AND MOTIVATION OF POST STROKE PATIENTS IN MEDICAL REHABILITATION TRAINING AT MEDICAL REHABILITATION ROOM OF PROVINCE GENERAL HOSPITAL OF NTB 2019}

\begin{abstract}
Stroke rehabilitation is a very important part of recovery efforts in post-stroke patients. Rehabilitation of Stroke can help Stroke patients in many ways, namely building strength, coordination, endurance or resilience and self-confidence. The purpose of this study was to determine the relationship between family support and the motivation of stroke patients in conducting medical rehabilitation training. The study design was correlative design with a sample of 50 people. This research was conducted at Medical Rehabilitation Room of Province General Hospital of NTB in July 2019. The data collection tool in this study was a questionnaire. Based on the results of the study, most of the respondents were in the age range of 45-59 years, namely 26 (53.1\%), men with the number 27 (55\%), 21 did not have school education (42\%), had good family support as many as 33 (66\%), had good motivation as much as $30(60 \%)$ and based on
\end{abstract}


the results of the spearmank rank test obtained $P$ value 0,000 which means $\alpha<0.1$ so that it can be concluded that there is a Relationship between Family Support and Motivation of Post-Stroke Patients in Performing Medical Rehabilitation Exercises in the Polyclinic of the Provincial Hospital of NTB in 2019. Suggestions are expected that the results of this study can be used to enrich the development of science especially in the field of nursing

Keywords: Family Support, Motivation, Medical Rehabilitation

\section{PENDAHULUAN}

Kemajuan peradaban manusia sudah semakin berkembang pesat di segala bidang kehidupan.Ilmu pengetahuan dan teknologi dewasa ini menjadi bagian yang tidak terpisahkan dari kehidupan masyarakat modern. (Irfan, 2010)

Data World Health Organization (WHO) menunjukan sekitar $31 \%$ dari 56.5 juta orang atau 17.7 juta orang diseluruh dunia meninggal akibat penyakit jantung dan pembuluh darah. Dari seluruh kematian akibat penyakit kardiovaskuler, sebesar 7.4 juta disebabkan oleh penyakit jantung coroner dan 6.7 disebabkan oleh Stroke (WHO, 2013).

Prevalensi Stroke nasional berdasarkan Riskesdas 2013 sebesar 12.1\% tertinggi di provinsi Sulawesi Selatan (17.9\%) dan terendah di Papua barat, Lampung. Dan Jambi (5.3\%). Diperkirakan pada tahun 2013 terdapat sekitar 3 juta orang menyandang stroke di Indonesia (Riskesdas,2013).

Kejadian stroke di NTB terjadi karena beberapa faktor resiko diantaranya hipertensi dan obesitas.Pemeriksaan terhadap factor resiko dan ataupun obesitas dilakukan di Puskesmas dan jaringannya. Dari 8 kabupaten di provinsi NTB yang terdeteksi obesitas didapatkan 16.268 orang $(4.68 \%)$ dari 347.316 orang yang dilakukan pemeriksaan. (Profil NTB, 2017).

Upaya latihan gerak atau ROM pada pasien pasca Stroke akan tercapai manakala individu termotivasi untuk mencari kebutuhan pada tahap yang lebih tinggi, sehingga individu akan mempunyai tahap yang lebih tinggi, sehingga individu akan mempunyai kemampuan dalam memecahkan masalah (Tamher, 2009).

Berdasarkan latar belakang diatas penulis tertarik untuk menyusun Skripsiyang berjudul "Hubungan Dukungan Keluarga dengan Motivasi Pasien Pasca Stroke dalam Melakukan Latihan Rehabilitasi Medik di Poliklinik RSUD Provinsi NTB Tahun 2018”.

Tujuan penelitian: Untuk mengetahui hubungan Hubungan Dukungan Keluarga dengan Motivasi Pasien Pasca Stroke dalam Melakukan Latihan Rehabilitasi Medik di Poliklinik RSUD Provinsi NTB Tahun 2019.

\section{BAHAN DAN METODE}

Desain penelitian yang digunakan adalah analitik korelasional dimana peneliti mencoba menggali hubungan sedemikian rupa mengenai mengapa suatu fenomena bisa terjadi (Imron, M.2014). Penelitian ini dilakukan pada bulan Juli tahun 2019. Populasi dalam penelitian ini adalah pasien post stroke pada bulan Januari dan Februari 2019 di Poliklinik rehabilitasi medik RSUD Provinsi NTB yaitu sebanyak 98 pasien. Dengan jumlah sampel 50 orang menggunakan tehnik sampling Purposive sampling. Instrumen penelitian menggunakan kuesioner dukungan keluarga sebanyak 20 item 
pertanyaan dan kuesioner motivasi sebanyak 10 item pernyataan

\section{HASIL DAN BAHASAN}

Karakteristik demografi responden Distribusi responden berdasarkan umur.

Distribusi frekuensi responden berdasarkan umur di poli Rehab Medik RSUD Provinsi NTB Tahun 2019

\begin{tabular}{lcc}
\hline Umur & Frekuensi & Persentase (\%) \\
\hline $\mathbf{4 5 - 5 9}$ & 26 & $\mathbf{5 3 . 1}$ \\
\hline $\mathbf{6 0 - 7}$ & 19 & 38.8 \\
\hline $\mathbf{7 5 - 9 0}$ & 5 & 8.2 \\
\hline Total & 50 & 100
\end{tabular}

Sumber : Data Primer

Berdasarkan tabel diatas mengatakan sebagian besar responden berada pada rentang umur 45-59 tahun yaitu sebanyak $26(53.1 \%)$ dan yang terendah pada umur 75-90 tahun sebanyak $5(8.2 \%)$

Distribusi responden berdasarkan jenis kelamin Distribusi frekuensi responden berdasarkan jenis kelamin di poli Rehab Medik RSUD Provinsi NTB Tahun 2019

\begin{tabular}{lcc}
\hline Jenis Kelamin & Frekuensi & Persentase (\%) \\
\hline Perempuan & 23 & 46 \\
\hline Laki-laki & 27 & 54 \\
\hline Total & 50 & 100
\end{tabular}

Sumber : Data Primer

Berdasarkan tabel diatas dapat diketahui bahwa sebagian besar responden adalah laki-laki dengan jumlah $27(54 \%)$ dan yang terendah adalah wanita yaitusebanyak 23 (46\%).

Distribusi responden berdasarkan pendidikan

Distribusi frekuensi responden berdasarkan pendidikan di poli Rehab Medik RSUD Provinsi NTB Tahun 2019

\begin{tabular}{lll} 
Pendidikan & Frekuensi & Persentase(\%) \\
\hline TS & 21 & 42 \\
\hline SD & 12 & 24 \\
\hline SMP & 3 & 6 \\
\hline SMA & 7 & 14 \\
\hline PT & 7 & 14 \\
\hline Total & 50 & 100 \\
\hline
\end{tabular}

Sumber : Data Primer

Berdasarkan tabel diatas mengatakan bahwa sebagian besar responden berpendidikan tidak sekolah sebanyal 21 $(42 \%)$ dan yang terendah berada pada pendidikan SMP sebanyak $3(6 \%)$.

\section{Identifikasi Dukungan Keluarga responden Dukungan keluarga keluarga di poli Rehab Medik RSUD Provinsi NTB Tahun 2019}

\begin{tabular}{lcc}
\hline $\begin{array}{l}\text { Dukungan } \\
\text { Keluarga }\end{array}$ & Frekuensi & Persentase (\%) \\
\hline Baik & 33 & 66 \\
\hline Cukup & 11 & 22 \\
\hline Kurang & 6 & 12 \\
\hline Total & 50 & 100
\end{tabular}

Sumber : Data Primer

Berdasarkan data diatas diketahui sebagian besar responden memiliki dukungan keluarga yang baik sebanyak 33 (66\%) dan yang terendah memiliki dukungan keluarga kurang sebanyak 6 $(12 \%)$.

Motivasi Pasien Pasca Stroke dalam Melakukan Latihan Rehabilitasi Medik di poli Rehab Medik RSUD Provinsi NTB Tahun 2019

\begin{tabular}{lcc}
\hline Motivasi & Frekuensi & $\begin{array}{l}\text { Persentase } \\
(\boldsymbol{\%})\end{array}$ \\
\hline Baik & 30 & 60 \\
\hline Cukup & 5 & 10 \\
\hline Kurang & 15 & 30 \\
\hline Total & 50 & 100 \\
\hline
\end{tabular}

Berdasarkan data di atas diketahui sebagian besar responden memiliki 
motivasi yang baik sebanyak 30 (60\%) dan yang terendah memiliki motivasi cukup sebanyak 5 (10\%).

Berdasarkan data di atas diketahui bahwa P Value 0.000 yang artinya $\alpha<0.1$ sehingga dapat disimpulkan bahwa ada Hubungan Dukungan Keluarga dengan Motivasi Pasien Pasca Stroke dalam Melakukan Latihan Rehabilitasi Medik di Poliklinik RSUD Provinsi NTB Tahun 2019.

\section{Dukungan Keluarga}

Berdasarkan hasil penelitian sebagian besar responden memiliki dukungan keluarga yang baik sebanyak $33(66 \%)$ dan yang terendah memiliki dukungan keluarga kurang sebanyak $6(12 \%)$.

Pemenuhan kebutuhan-kebutuhan yang diperlukan pada pasien stroke, peran orang terdekat atau dukungan dari keluarga sangatlah dibutuhkan agar terpenuhinya semua kebutuhan pasien stroke. Dukungan keluarga yang kurang akan cenderung menyebabkan kualitas hidup pasien stroke menjadi kurang pula (Sunniati, 2014).

Hayulita dan Desti (2014) juga menyatakan bahwa pada pasien pasca stroke yang memiliki dukungan keluarga yang tidak baik memiliki presentase tingkat depresi yang tinggi $(79,4 \%)$. Kurangnya dukungan keluarga pada pasien stroke akan membuat kualitas hidup pasien stroke menjadi rendah dan juga dapat mengakibatkan pasien stroke menjadi depresi.

Dukungan keluarga sendiri merupakan segala bentuk perilaku dan sikap positif yang diberikan keluarga kepada salah satu anggota yang sakit (Tumenggung, 2013).Bentuk dukungan keluarga yang bisa diberikan keluarga yaitu terdiri dari dukungan informatif, dukungan penilaian atau penghargaan, dukungan emosional, dan dukungan instrumental atau tambahan.

Hasil penelitian ini sesuai dengan hasil penelitian yang dilakuka di RSU
HKBP Balige dimana hasil penelitian menunjukkan lebih dari separuh pasien pasca stroke mempunyai dukungan keluarga baik namun masih ada yang mendapat dukungan keluarga cukup, hal ini dapat terjadi karena kurangnya kepedulian antar sesama anggota keluarga atau bisa juga terjadi karena keterbatasan keluarga untuk selalu meluangkan waktu serta memperhatikan anggota keluarga pasien pasca Stroke untuk melakukan terapi ROM.

\section{Motivasi}

Berdasarkan data diatas diketahui sebagian besar responden memiliki motivasi yang baik sebanyak $30(60 \%)$ dan yang terendah memiliki motivasi cukup sebanyak 5 (10\%).

Sejalan dengan penelitian Manurung. M (2017) menunjukkan bahwa motivasi pasien pasca stroke untuk melakukan ROM di RSU HKBP Balige tinggi untuk melakukan ROM, dimana sebanyak 11 orang $(64.7 \%)$ memiliki motivasi yang baik dalam melakukan ROM dan sebanyak 6 orang (35.3\%) memiliki motivasi yang cukup dalam melakukan ROM.

\section{Analisa Hubungan Dukungan keluarga dengan motivasi}

Berdasarkan data diatas diketahui bahwa $P$ Value 0.000 yang artinya $\alpha<0.1$ sehingga dapat disimpulkan bahwa ada Hubungan Dukungan Keluarga dengan Motivasi Pasien Pasca Stroke dalam Melakukan Latihan Rehabilitasi Medik di Poliklinik RSUD Provinsi NTB Tahun 2019.

Dukungan keluarga merupakan segala bentuk perilaku dan sikap positif yang diberikan keluarga kepada salah satu anggota yang sakit yaitu anggota keluarga yang mengalami masalah kesehatan (Tumenggung, 2013).

Dukungan keluarga juga akan memberikan dampak kesehatan fisik dan mental pada anggota kelurga yang sakit 
bahkan rendahknya dukungan keluarga yang diberikan secara konsisten berhubungan dengan meningkatnya angka kesakitan dan kematian (Saputera, dkk., 2015). Dukungan keluarga yang diberikan kepada pasien stroke akan memotivasi atau mendorong mereka untuk rutin mengikuti rehabilitasi dan juga akan membantu meningkatkan kondisi kesehatan fisik dan mentalnya.

Dalam penelitian Manurung (2017) menyimpulkan dukungan keluarga mempengaruhi motivasi penderita stroke dalam melakukan latihan, juga berpengaruh besar dalam peningkatan kekuatan oto dengan hasil penelitian nilai $\mathrm{p}=0.001$ yang berarti ada hubungan yang signifikan antara hubungan dukungan keluarga dengan motivasi dalam melakukan ROM pada pasien pasca stroke di RSU HKBP Balige dengan kekuatan hubungan rendah dan dengan arah korelasi positif. Hasil penelitian Nuryanti. S (2016) juga menemukan bahwa ada hubungan yang signifikan dukungan keluarga (dukungan informasi, dukungan emosional, dukungan instrumental, dukungan penghargaan) dengan motivasi melakukan Range Of Motion (ROM) pada pasien pasca stroke di RSUD Kanudjoso Djatiwibowo Balikpapan tahun 2016.

\section{SIMPULAN DAN SARAN}

\section{Kesimpulan}

Berdasarkan hasil penelitian didapatkan bahwa $P$ Value 0.000 yang artinya $\alpha<0.1$ sehingga dapat disimpulkan bahwa ada Hubungan Dukungan Keluarga dengan Motivasi Pasien Pasca Stroke dalam Melakukan Latihan Rehabilitasi Medik di Poliklinik RSUD Provinsi NTB Tahun

\section{Saran}

Diharapkan hasil penelitian ini dapat digunakan untuk memperkaya perkembangan ilmu khususnya dalam bidang keperawatan.

\section{DAFTAR PUSTAKA}

Brunner, S. (2004). Buku Ajar Keperawatan Medical Bedah.Jakarta : EGC.

Carr, A . (2003). Positive pshichology: the science of happiness and human strength. Hove \& newyork:Brunner - Routledge taylor \& Francis Group.

Friedman, L.M. (2010). Buku Ajar Keperawatn keluarga.Jakarta : EGC.

Ghifari, Al. M. \& Adinda, M. (2017).Gambaran Tekanan Darah pada Pasien Stroke Akut di Rumah Sakit Umum Haji Medan Tahun 2015.Http://jurnal.umsu.ac.id/index. php/buletin_farmatera Vol 2 no 2.

Hamzah, H. (2008).Teori motivasi dan pengukurannya: analisis di bidang Pendidikan edisi 1. Jakarta: bumi aksara.

Hidayat, R. (2016). Pengaruh pengetahuan dan dukungan keluarga terhadap kepatuhan menjalani neurorehabilitasi pada pasien pasca stroke di unit rehabilitasi medik rsudza banda aceh.Chaira et al. Jurnal Ilmiah Mahasiswa Medisia Vol. 1 No. 4: 12-17.

Hidayati, N. Violita, V. (2015).Peran pendampingan keluarga pasien stroke dengan motivasi pasien melaksanakan rom aktif.Journals of Ners Community Volume 6.

Imron, M. (2014). Metodologi Penelitian Bidang Kesehatan. Edisi 2. Jakarta : Penerbit Sagung Seto

Irfan.(2010). Fisiotterapi Bagi Insan Stroke.Yogykarta :Graha ilmu.

Iskandar, J. (2008). Panduan praktisi Pencegahan dan pengobatan Stroke. Edisi I. PT Bhuana Ilmu Popule

Kemenkes, RI. (2017). Profil kesehatan Indonesia 2016.klinis untuk hasil yang diharapkan (ed. 8 vol. 3). Singapura: Elsevier

Manurung, M. (2017). Dukungan Keluarga dengan Motivasi dalam Melakukan ROM Pada Pasien 
Pasien Stroke di RSU HKBP Balige Kabupaten Toba Samosir.Idea Nursing Journal Volume VIII, Nomor 3.

Medical Record RSUD Provinsi NTB . (2018). Pravelensi kejadian kanker payudara. Mataram : RSUD Provinsi NTB.

Muarandari, A \& Tri Wahyuliati. (2014).Efikasi Fisioterapi terhadap Perbaikan Derajat Paresis Berdasarkan Status Ekonomi Penderita Stroke. Mutiara Medika, Volume 14 No 1: 33-38.

Notoadmojo.(2012). Pendidikan dan Perilaku Kesehatan. Jakarta: PT Rhineka Cipta.

Nugraha, A. Dkk. (2017).Dukungan keluarga dalam memotivasi pasien untuk melakukan mobilisasi pasca stroke di rumah sakit umum (RSUD) Dr. Slamet Kab.Garut.Jurnal poltekkes provinsi benguku vol. 3 no. 7

Nursalam.(2012). Konsep dan Penerapan Metodologi Penelitian Ilmu Keperawatan. Jakarta: Salemba Medika.

Nuryanti, S. (2016). Hubungan antara dukungan keluarga dan motivasi melakukan rom pada pasien pasca stroke. Mahakam Nursing Journal Vol 1.

Profil Provinsi Nusa Tenggara Barat, Tahun 2017

Riskesdas.(2013). Badan Penelitian dan PengembanganKesehatan

Kementerian RI tahun 2013.Diakses pada tanggal $30 \quad \mathrm{Mei}$ 2018.http://www.depkes.go.id/resou rces/download/general/hasil\%20Ris kesdas\%202013.pdf.

Sunniati, E. (2014). Hubungan Dukungan Keluarga dengan Kualitas Hidup Pasien Stroke di Ruang Rehabilitasi Medik Rumah Sakit Umum Daerah dr. Zainoel Abidin Banda Aceh. Skripsi Fakultas Keperawatan,
Universitas Syiah Kuala, Banda Aceh.

Tamher, S. \& Noorkasiani. (2009). Kesehatan Usia Lanjut dengan Pendekatan Asuhan Keperawatan. Jakarta : Salemba Medika.

Tumenggung, I. (2013). Hubungan Dukungan Sosial Keluarga dengan Kepatuhan Diet Hipertensi DI RSUD Toto Kabila Kabupaten Bone Bolongo, Vol 1.

WHO. (2013). Cardiovascular diseases. World Health Organization. Geneva Available from URL: http://www.who.int/cardiovascular_ diseases/about_cvd/en/ accessed on. 